J Ästhet Chir 2011 • 4:103-103

DOI 10.1007/s12631-011-0140-5

Online publiziert: 6. Juli 2011

(c) Springer-Verlag 2011

C. Schrank

Aesthetik am Ammersee, Privatklinik Dr. Schindlbeck, Herrsching am Ammersee

\title{
Anspruch und Verantwortung der Faceliftchirurgie
}

gressen, in Fachzeitschriften oder bei persönlichen Gesprächen, eröffnen die Möglichkeit, Techniken weiterzuentwickeln, Grenzen, Risiken und Gefahren neuer Therapieansätze zu erörtern und „Katastrophen" bei der Behandlung unserer Patienten zu vermeiden.

Die "Neuzeit" der Faceliftchirurgie liegt in den 7oer-Jahren und begann mit der Entwicklung der SMAS-Technik. Innerhalb der letzten 40 Jahre ist diese Methode so weiterentwickelt und verfeinert worden, dass die Behandlungsergebnisse ihresgleichen suchen. An ihr müssen sich alle neuen Techniken oder alternativen Therapieansätze messen und den Beweis erbringen, besser zu sein oder langjährige Verbesserungen zu erreichen. Andernfalls fallen wir in der Entwicklung wieder um Jahrhunderte zu den Gründungsvätern der plastisch-ästhetischen Chirurgie zurück.

Ebenfalls weiterentwickelt hat sich das funktionelle und topographisch-anatomische Verständnis des Gesichts- und Halsbereichs. Inventionen aus der Unfallund kraniofazialen Chirurgie führten in der Mund-Kiefer-Gesichtschirurgie dazu, dass durch Eingriffe in das knöcherne Grundgerüst ästhetische Gesichtsproportionen wiederhergestellt bzw. harmonisiert werden können. Skelettale Bewegungen stellen eine Möglichkeit der Beeinflussung der Gesichtsweichteile dar.

Jeder von uns hat ein ganz eigenes Gesicht mit spezifischen Facetten, das in seiner Individualität erhalten bleiben soll. Deshalb liegt die große Kunst bei der Behandlung des alternden Gesichts darin, die Natur und ihre harmonischen Formen bestmöglich zu imitieren.



Christian Schrank

\section{Korrespondenzadresse \\ Dr. C. Schrank}

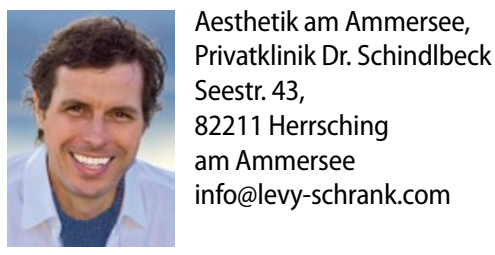

